Artigo original

Hegemonia - Revista Eletrônica de Relações Internacionais do Centro Universitário Unieuro

ISSN: $1809-1261$

UNIEURO, Brasília, número 15, 2015, pp. 68-87.

Recebido em: 15/4/2015

Avaliado em:1/5/2015

Aprovado em: 11/6/2015

\title{
Dilma Rousseff 2: Determinantes de las elecciones presidenciales de 2014 y la calidad de la democracia en Brasil
}

Simone Rodrigues Pinto ${ }^{1}$ e Carlos Federico Domínguez Avila²

Resumo: $O$ artigo explora os principais determinantes e os resultados das eleições brasileiras de 2014, bem como a assunção do novo governo. Esse processo eleitoral culminou com os dois turnos - 5 e 26 de outubro - e a reeleição de Dilma Rousseff, do Partido dos Trabalhadores (PT). Além da disputa presidencial, os comícios também resultaram em mudanças e continuidades no Parlamento e nos governos estaduais. A manutenção dos PT e de seus aliados no governo federal do Brasil terá importantes repercussões internas e internacionais. $\mathrm{O}$ artigo inclui quatro subtítulos. $\mathrm{O}$ primeiro subtítulo comenta alguns aspectos centrais da evolução recente do sistema políticoeleitoral. O segundo subtítulo explora a virtual polarização vigente entre os dois principais blocos político-eleitorais do país. $O$ terceiro subtítulo discorre sobre a candidatura presidencial de Eduardo Campos e Marina Silva. E o seguinte

Doutora em Ciência Política, docente da Universidade de Brasília.

Doutor em História, docente e pesquisador do Mestrado em Ciência Política do Centro Universitário Unieuro (Brasília). 
Artigo original

Hegemonia - Revista Eletrônica de Relações Internacionais do Centro Universitário Unieuro

ISSN: $1809-1261$

UNIEURO, Brasília, número 15, 2015, pp. 68-87.

subtítulo analisa os resultados das eleições de 2014 e a assunção do novo governo.

Palavras-chave: Brasil; Eleições Gerais; Qualidade da Democracia; Sistema Político.

Abstract: This paper explores the main determinants and outcomes of Brazilian elections of 2014. That electoral process culminated in the two rounds October, $5^{\text {th }}$ and $26^{\text {th }}$ - and the reelection of Dilma Rousseff, of the Workers Party (PT). In addition to the presidential race, the elections have also resulted in changes and continuities in Parliament and state governments. The maintenance of the PT and its allies in the federal government will have important domestic and international repercussions. The article includes four subtitles. The first subtitle says some central aspects of the recent evolution of the country and its electoral system. The second explores the virtual polarization between the two main political-electoral blocs in the country. The third subtitle discusses the candidacy of Eduardo Campos and Marina Silva. The following statement addresses the results of the 2014 elections and the inauguration of the new government.

Key words: Brazil; General Elections; Quality of Democracy; Political System.

Resumen: El presente artículo explora los principales determinantes y los resultados de las elecciones brasileñas de 2014, además de la asunción del nuevo gobierno. Ese proceso electoral culminó con las dos vueltas -5 y 26 de octubre - y con la reelección de Dilma Rousseff, del Partido de los Trabajadores (PT). Además de la disputa presidencial, los comicios también resultaron en cambios y continuidades en el Parlamento y en gobierno estaduales o provinciales. La manutención del PT y sus aliados en el gobierno federal del Brasil tendrá importantes repercusiones internas e internacionales. El artículo incluye cuatro subtítulos. El primer subtítulo comenta algunos aspectos centrales de la evolución reciente del país y de su sistema electoral. El segundo subtítulo explora la virtual polarización vigente entre los dos principales bloques político-electorales del país. El tercer subtítulo discute la sorpresiva candidatura presidencial de Eduardo Campos y Marina Silva. El siguiente subtítulo aborda los resultados de las elecciones de 2014 y la asunción del nuevo gobierno.

Palabras-clave: Brasil; Elecciones Generales; Calidad de la Democracia; Sistema Político. 
Artigo original

Hegemonia - Revista Eletrônica de Relações Internacionais do Centro Universitário Unieuro

ISSN: $1809-1261$

UNIEURO, Brasília, número 15, 2015, pp. 68-87.

Introducción: breves consideraciones sobre la evolución reciente

Las elecciones presidenciales brasileñas de octubre de 2014 generaron una significativa expectativa doméstica y continental. Aunque finalmente las urnas terminaron favoreciendo a la candidata Dilma Rousseff, del Partido de los Trabajadores (PT), los resultados de las dos vueltas - celebradas en 5 y 26 de octubre, respectivamente - fueron mucho más apretados de lo que los analistas y observadores vaticinaban. Obsérvese, por ejemplo, que la diferencia entre Dilma Rousseff y su adversário, Aécio Neves, del Partido de la SocialDemocracia Brasileña (PSDB), en la segunda vuelta fue de apenas 3\% de los votos válidos. En consecuencia, no pocos cientistas políticos y sociales las han calificado como uno de los procesos electorales más disputados y polarizados desde el retorno al orden democrático, en 1985 (Mainwaring, 2001).

¿Qué estaba en juego en las elecciones presidenciales brasileñas de 2014? Fundamentalmente se trataba de la continuidad (o no) del proyecto socialpopular impulsado desde la asunción de Luiz Inácio Lula da Silva (2003-2010) y sustentado por Dilma Rousseff (2011-2014), ambos del PT y dirigentes de una alianza de partidos de centro-izquierda. En contraposición, Aécio Neves, candidato del PSDB, cuestionaba, desde posturas de centro-derecha, la hegemonía petista en el país.

Séptima economía del mundo, el Brasil también es una república federativa, presidencialista y de orientación democrática. Desde el retorno al régimen democrático fueron realizados siete procesos electorales de naturaleza presidencial - que es el que más interesa para los fines del presente artículo. En octubre de 2014, fueron convocados 142,8 millones de electores - esto es, el tercer mayor censo electoral del mundo, solamente superado por la India y por los Estados Unidos. Y más de 25 mil candidatos disputaron más de 1500 cargos electivos, incluyendo la Presidencia de la República, toda la Cámara de Diputados, un tercio del Senado, y 27 gobiernos estaduales (y del Distrito Federal).

Vale señalar que, actualmente, el sistema político brasileño incluye 32 partidos políticos legalmente reconocidos, inscritos y casi todos con algún 
Artigo original

Hegemonia - Revista Eletrônica de Relações Internacionais do Centro Universitário Unieuro

ISSN: $1809-1261$

UNIEURO, Brasília, número 15, 2015, pp. 68-87.

representante en el Parlamento - la legislatura de 2015 iniciará con representantes de 28 partidos políticos en el Congreso (Braga, 2010). Los principales partidos políticos son el PT, el PSDB, el Partido Movimiento Democrático Brasileño (PMDB, de centro), el Partido Social Democrático (PSD de centro-derecha) y el Partido Socialista Brasileño (PSB, de centro-izquierda).

La mayoría de los partidos políticos brasileños es bastante pragmática y casi siempre termina ofreciendo su apoyo parlamentar al Ejecutivo. Este último es tópico de fundamental relevancia en el presidencialismo de coalición vigente en el país. Acontece que, para conseguir un mínimo de gobernabilidad, los presidentes deben formar coaliciones mayoritarias en el Parlamento. Asimismo, los partidos aliados también ofrecen mayor cantidad de tiempo en el denominado Horario Gratuito de Propaganda Electoral - que es definido, al menos para la primera vuelta, en función de los diputados que tales aliados logran elegir en el Parlamento (Telles e Moreno 2013). Igualmente, los partidos aliados pueden ayudar a penetrar en determinados núcleos electorales específicos (Santander et alli, 2014).

En compensación, los partidos aliados normalmente demandan del Ejecutivo influencia, cargos gubernamentales y acceso privilegiado a ciertos recursos del Estado. ${ }^{3}$ Unirse a las candidaturas victoriosas también puede ser una garantía de sobrevivencia y otros beneficios que estas pequeñas y medias organizaciones políticas difícilmente alcanzarían si decidiesen presentarse con candidaturas exclusivas. Los partidos más exitosos en ese sentido pragmático son aquellos con bancadas numerosas, los ubicados en el centro ideológico, los que cuentan con poderosas corrientes internas, y aquellos que terminan siendo multifacéticos.

Así como acontece en muchos otros países del continente y del mundo, en el sistema político-partidario brasileño acaba predominando el pragmatismo. En consecuencia, resulta un tanto temerario intentar clasificar a los numerosos institutos políticos actuantes en el país de acuerdo con las grandes tradiciones ideológicas tradicionales. 
Artigo original

Hegemonia - Revista Eletrônica de Relações Internacionais do Centro Universitário Unieuro

ISSN: $1809-1261$

UNIEURO, Brasília, número 15, 2015, pp. 68-87.

También es apropiado recordar que los electores brasileños están distribuidos de forma desigual entre las macro-regiones y unidades federativas. El poderoso Estado de São Paulo, con 30 millones de electores, concentra 22\% del censo electoral del país. Otras importantes circunscripciones, por número de electores, son Minas Gerais, Rio de Janeiro, Bahía, y Rio Grande do Sul. Obsérvese, que $52 \%$ de los electores son mujeres, y $48 \%$ son hombres. Los jóvenes (16 a 34 años) representan 39\%, y los ancianos (más de 60 años) 17\%. $Y$ los electores brasileños residentes en el exterior son relativamente pocos, aproximadamente 300 mil.

En términos socioeconómicos, ocho de cada diez electores tienen ingresos que varían entre uno y cinco salarios mínimos (en 2014 el salario mínimo brasileño era equivalente a US $\$ 330$ mensuales). Ese estratégico segmento del electorado, integrado por aproximadamente 100 millones de votantes, también pasó a ser denominado como la nueva clase media brasileña. ${ }^{4}$ Muchos de los miembros de ese segmento del electorado es integrado por nuevos consumidores, con creciente poder adquisitivo (especialmente por la vía del acceso al crédito), con nuevas aspiraciones de movilidad social ascendente, y también preocupadas con la inflación, el empleo y las nuevas responsabilidades tributarias (Cepal, 2014).

Obsérvese que tales datos son sumamente importantes en términos de sociología política, ya que una de las principales banderas electorales levantadas por la candidatura oficialista reivindicaba la necesidad de dar continuidad a los programas de desarrollo social impulsados por el PT, desde 2003 (Ipea, 2012). Tal es el caso del programa de transferencia de ingreso (denominado Bolsa Família), y de políticas sectoriales (construcción de viviendas populares, atención a la salud, programas educativos, electrificación rural, entre otros). Fue así que, en la última década, el Brasil consiguió

"Todos os candidatos querem o voto de Keila", El Pais, 6.9.2014, disponible en: www.elpais.com.br. Acceso el 3 de noviembre de 2014. 
Artigo original

Hegemonia - Revista Eletrônica de Relações Internacionais do Centro Universitário Unieuro

ISSN: $1809-1261$

UNIEURO, Brasília, número 15, 2015, pp. 68-87.

significativos progresos en favor de la inclusión social, de la lucha contra el hambre y la miseria. Los principales indicadores de extrema pobreza, por ejemplo, manifestaron una sensible caída del $28 \%$ de la población en 2003 , para el $8 \%$ en 2014 . Se entiende, así, la significativa adhesión de los sectores subalternos, de las clases populares, y de ciertas macro-regiones del país, a la candidatura oficialista. Actualmente no cabe duda de la fuerte penetración del Partido de los Trabajadores y de otros partidos oficialistas en la periferia de las grandes ciudades - siendo que $70 \%$ de la población brasileña viven las áreas urbanas -, y en zonas rurales del Norte y Nordeste del país.

La oposición y analistas de orientación liberal, por su parte, cuestionaron no solamente la pesada carga fiscal generada por aquellos programas de desarrollo social, como también el uso político-electoral derivado en beneficio de la candidata oficialista - y que, además, era candidata a reelección. A ese respecto, vale tener presente que Brasil mantiene una de las más altas cargas tributarias en América Latina - más de $30 \%$ del producto. Además, en los últimos años hubo frecuentes denuncias de corrupción, con destaque para el denominado escándalo del Mensalão, episodio que, en 2005-2006, casi provocó la caída de Lula, y que consistía en el desvío de recursos públicos para financiar el apoyo de partidos aliados en el Parlamento (Moisés, 2010). Al mismo tiempo, las candidaturas opositoras también criticaron las tendencias macroeconómicas del país, principalmente el bajo crecimiento del producto durante el primer gobierno de Dilma Rousseff (media de 1,6 anual entre 2011 y 2014), la persistencia de presiones inflacionarias, y crecientes tasas de interés básico. Todo ello en un difícil contexto económico internacional, determinado por la crisis financiera vigente en diferentes países capitalistas desde 2008.

En términos sociales, es importante tomar nota de los cuestionamientos referentes a la calidad de los servicios públicos - especialmente del transporte, de la salud y de la educación - que terminaron impulsando las denominadas Jornadas de Junio-Julio de 2013. Esa demostración de numerosos sectores de la sociedad brasileña con relación al conjunto de la clase política alcanzó enorme trascendencia, en el marco de la realización de importantes eventos deportivos, como la Copa del Mundo de 2014, que demandaron enormes gastos del gobierno. 
Artigo original

Hegemonia - Revista Eletrônica de Relações Internacionais do Centro Universitário Unieuro

ISSN: $1809-1261$

UNIEURO, Brasília, número 15, 2015, pp. 68-87.

Digna de mención es también la tecnología electoral utilizada en los últimos procesos. Acontece que, desde 1996, las autoridades electorales del país implementaron la llamada urna electrónica, y continúan realizando un paradigmático proceso de automatización de las diferentes etapas de los comicios, principalmente lo concerniente a la identificación de los electores, al ejercicio del voto, su escrutinio, y la divulgación de los resultados con la correspondiente seguridad, transparencia y rapidez. A grosso modo, la urna electrónica es una máquina que tiene una pantalla, un teclado numérico y una memoria que consigue registrar los números de identificación de los candidatos votados por los electores - siendo que los números de identificación de los candidatos fueron previamente designados por las autoridades electorales correspondientes. En las elecciones de octubre de 2014, fueron utilizadas más de 500 mil urnas electrónicas, instaladas en más de 400 mil centros de votación, localizados en más de 5500 municipios.

Ciertamente, los avances alcanzados por el Brasil en materia de tecnología electoral merecen respeto y admiración dentro y fuera del país. Así, normalmente los observadores internacionales que son invitados a acompañar los comicios brasileños expresan particular interés por ese aspecto de una democracia de calidad (Morlino, 2011). Y las innovaciones continúan en las elecciones de 2014, dado que ese año se propuso aplicar también la denominada tecnología biométrica, que consiste resumidamente en garantizar la identificación de los electores por medio de la verificación de su retrato y especialmente de sus huellas dactilares - previamente recolectadas y almacenadas en una base de datos - antes del ejercicio del voto. En tal sentido, las autoridades electorales, encabezadas por el Tribunal Supremo Electoral, continuaran marcando paso en la modernización de las elecciones latinoamericanas.

La polarización PT-PSDB

Seis de los siete procesos electorales presidenciales realizados en Brasil, entre 1989 y 2014, han sido protagonizados pos alianzas político-partidarias 
Artigo original

Hegemonia - Revista Eletrônica de Relações Internacionais do Centro Universitário Unieuro

ISSN: $1809-1261$

UNIEURO, Brasília, número 15, 2015, pp. 68-87.

encabezadas respectivamente por el Partido de los Trabajadores (PT, de centro-izquierda) y por el Partido de la Social-Democracia Brasileira (PSDB, de centro-derecha). Curiosamente, el PT y el PSDB surgieron en la década de 1980, en el contexto de la transición democrática y de la lucha común contra el legado del régimen burocrático-autoritario anterior. Obsérvese que muchas de las principales personalidades de estos partidos son antiguos correligionarios, con destaque para Lula y Cardoso. Sea como fuere, a partir de las elecciones de 1994, se inició una polarización entre ambos institutos políticos que se mantiene hasta el presente (D’Araújo, 2009). En las elecciones de 1994 y de 1998 se verificaron victorias del PSDB (que llevaron y mantuvieron en el poder a Fernando Henrique Cardoso), seguidas de victorias del PT en 2002, 2006, 2010 y 2014 (en beneficio de Lula y de Dilma Rousseff, ambos reelectos).

En 2014, Dilma Rousseff ha intentado construir la imagen de una buena gestora y heredera de la era Lula. Una gobernante que pretende cuidar y velar por los segmentos más vulnerables, además de construir el buen vivir para toda la sociedad. En esa línea, la propaganda del PT ha difundido la relevancia de las políticas sociales, de la redistribución del ingreso, de la reducción de las desigualdades, de la inclusión social, y de la lucha contra la miseria. En contraposición, la propaganda de la oposición política - especialmente del PSDB - ha cuestionado los frecuentes escándalos de corrupción que asolaron los 12 años de hegemonía petista. También existen dudas con relación a la consistencia de las tendencias macroeconómicas (inflación, estagnación del producto).

Vale agregar que en las elecciones de octubre de 2014 ambos partidos nuevamente encabezaron significativas alianzas con otros institutos políticos. El PT estableció alianzas con nueve partidos, y el PSDB con nueve instituciones. Es importante mencionar que la legislación electoral vigente no obliga a una consistente verticalización o reproducción de las alianzas federales en los procesos electorales sub-nacionales. Ello deriva en situaciones contradictorias y conflictivas, por cuanto no faltan casos de divergencias locales entre candidatos provinciales que, en nivel federal, son aliados. En tal sentido, algunos analistas sostienen que la única elección realmente nacional es para la Presidencia de la República (Cairrerão e Kinzo, 2010). 
Artigo original

Hegemonia - Revista Eletrônica de Relações Internacionais do Centro Universitário Unieuro

ISSN: $1809-1261$

UNIEURO, Brasília, número 15, 2015, pp. 68-87.

Es pertinente mencionar que la polarización PT-PSDB no excluye la participación de otras candidaturas presidenciales alternativas. En la primera vuelta de las elecciones de 2014 participaron once candidatos presidenciales: Dilma Rousseff (PT), Aécio Neves (PSDB), Marina Silva (PSB), Luciana Genro (Partido Socialismo y Libertad), Everaldo Dias Pereira (Partido Social Cristiano), Eduardo Jorge (Partido Verde), Mauro Iasi (Partido Comunista Brasileiro), Zé Maria (Partido Socialista de los Trabajadores Unificados), Levy Fidelix (Partido Renovador Laborista Brasileiro), José Maria Eymael (Partido Social DemócrataCristiano), y Rui Costa Pimenta (Partido de la Causa Operária). Dado que ninguno de los mencionados candidatos obtuvo la mitad más uno de los votos válidos, los dos más votados - quiere decir, Dilma Rousseff y Aécio Neves acabaron pasando a la segunda vuelta, y reeditando la polarización PT-PSDB.

Mismo siendo el voto obligatorio en Brasil, casi el $20 \%$ de los electores se abstuvieron de ejercer el sufragio en los últimos procesos electorales. Algo parecido aconteció con los electores que votaron en blanco o anularon sus votos. Así, casi $30 \%$ de los electores brasileños manifestaron, directa e indirectamente, persistente desafección ante los procesos electorales (Latinobarómetro, 2013). Ello conlleva, naturalmente, impactos negativos en la calidad de la democracia vigente en el país. Ciertos analistas y observadores sugieren que tal situación podría reflejar, también, un protesto contra la polarización PT-PSDB supra-citada. He ahí una oportunidad de crear una "tercera vía" político-partidaria. Esa alternativa fue explorada, con bastante suceso, por una candidata sui generis, Marina Silva.

La candidatura Eduardo Campos y Marina Silva: antecedentes y significados

Marina Silva es una de las personalidades políticas más importantes surgidas en Brasil, en la última década. Oriunda del amazónico Estado de Acre y procreada en el seno de una humilde familia de agricultores, ella inició su carrera política junto a la Central Única de Trabajadores. Se afilió al Partido de los Trabajadores en 1985, y pasó a propugnar especialmente en favor de la protección del medio ambiente y de los pueblos indígenas. Como candidata del PT logró 
Artigo original

Hegemonia - Revista Eletrônica de Relações Internacionais do Centro Universitário Unieuro

ISSN: $1809-1261$

UNIEURO, Brasília, número 15, 2015, pp. 68-87.

erigirse Senadora y, en 2003, fue invitada por Lula para participar en el Gabinete con el cargo de Ministra de Medio Ambiente. Vale acrecentar que en el mismo Gabinete también fue nombrada Dilma Rousseff, primero como Ministra de Minas y Energía y luego como Ministra-coordinadora de todo el Gabinete. De aquella época se recuerdan los embates entre Marina Silva y Dilma Rousseff, que finalmente resultaron en la salida de la primera tanto del Gobierno como del propio PT.

Con efecto, en 2009, Marina Silva fue invitada por el Partido Verde a asumir la candidatura a la Presidencia de la República. Así, ella acabó tornándose una de las mayores sorpresas en 2010, logrando casi 20 millones de votos, y asumiendo el tercer lugar entre los presidenciables (Limongi e Cortez, 2010). Posteriormente, divergencias en la conducción del Partido Verde resultaron en la salida de Marina Silva de ese instituto político, y la tentativa de crear un nuevo partido - de orientación ambientalista -, denominado Rede Sustentabilidade. Desafortunadamente, las autoridades electorales brasileñas no admitieron el registro del nuevo partido, obligando a Marina Silva a buscar otro partido que le pudiese abrigar al menos temporariamente, hasta conseguir el registro definitivo de su propio instituto político.

Paralelamente, Eduardo Campos, joven político oriundo de una tradicional familia del Estado de Pernambuco (Nordeste de Brasil), decidió, en 2013, separarse gradualmente de la hegemonía petista y, junto con su Partido Socialista Brasileiro (PSB), buscar erigirse como una "tercera vía" en el país. El proyecto de Eduardo Campos era desafiante, dado que el PSB era, en la época, un instituto de mediana proporción nacional, y la influencia política del propio Campos era poco conocida fuera del Estado de Pernambuco - donde fue Gobernador - y de las provincias adyacentes.

Fue en ese contexto que Eduardo Campos, en calidad de presidente del PSB, decidió apadrinar el ingreso de Marina Silva a su partido, designándola como Candidata a Vicepresidente en la fórmula que él mismo acabaría encabezando. Es bastante plausible suponer que Campos pretendía heredar en las elecciones de octubre de 2014 muchísimos de los votos que Marina Silva había conquistado en 2010. A su vez, Marina Silva, mismo que en segundo 
Artigo original

Hegemonia - Revista Eletrônica de Relações Internacionais do Centro Universitário Unieuro

ISSN: $1809-1261$

UNIEURO, Brasília, número 15, 2015, pp. 68-87.

plano, mantendría algún protagonismo nacional, y halagüeñas perspectivas futuras.

Sea como fuere, a inicios de agosto de 2014, ambos políticos encabezaban una coalición de seis medianos y pequeños partidos políticos - de centro y centro-izquierda. La aguardada transferencia de intenciones de votos marinistas para la candidatura de Campos aún no se demostraba en su plenitud. Ello colocaba a Campos en el tercer lugar de las intenciones de votos, con aproximadamente $8 \%$ de simpatía del electorado. Obsérvese que la situación del PSB era un tanto extraña, por cuanto la candidata a vicepresidente continuaba siendo mucho más popular que el titular de la candidatura. Para muchos observadores, Campos estaba, en realidad, preparando su candidatura también con perspectivas hacia 2018 , época en la que presumiblemente tendría mejores perspectivas de victoria.

Todo ese escenario político-electoral se transformó, dramáticamente, el 13 de agosto de 2014, con el deceso de Eduardo Campos, en un accidente aéreo. ${ }^{5}$ En el episodio, el PSB perdió no solamente a su presidente nacional, como también a su candidato presidencial. La muerte del joven político pernambucano provocó gran consternación en la sociedad y el Estado brasileño. Tres días de luto nacional fueron promulgados y todas las campañas electorales fueron suspendidas hasta el entierro de las víctimas del accidente.

Posteriormente, el PSB se avocó a difíciles decisiones concernientes a la campaña. La primera era sobre la propia manutención (o retirada) de la candidatura presidencial. Al respecto, parece importante ponderar que algunos líderes políticos llegaron a especular sobre la eventual reincorporación del PSB en la base de sustentación del PT, y con la consiguiente retirada de la

"O Brasil perde um jovem político", El Pais, 13.8.2014, disponible en: www.elpais.com.br. Acceso el 3 de noviembre de 2014. 
Artigo original

Hegemonia - Revista Eletrônica de Relações Internacionais do Centro Universitário Unieuro

ISSN: $1809-1261$

UNIEURO, Brasília, número 15, 2015, pp. 68-87.

candidatura presidencial. Finalmente se acordó mantener la candidatura presidencial con una nueva fórmula.

Surgió así una segunda y delicada cuestión sobre la composición de la nueva fórmula. Acontece que Marina Silva parecía ser la opción natural del PSB. Entretanto, algunas personalidades históricas del referido partido dudaban de las credenciales ideológicas de Marina Silva, quien entró en el PSB apadrinada por Campos y su grupo. Ciertos "históricos" del PSB, inclusive su nuevo presidente, Roberto Amaral, aparentemente pretendían retornar a la base de sustentación del PT, de donde habían salido por insistencia del proyecto político de Eduardo Campos, que buscaba erigirse en alternativa a la polarización PTPSDB y dejar abiertas las perspectivas para una candidatura presidencial aún más competitiva en 2018. Al final, la cúpula del PSB aceptó recomponer la candidatura presidencial encabezada por Marina Silva y secundada por Beto Albuquerque. ${ }^{6}$ Ahora sabemos que las diferencias intra-partidárias entre Marina Silva y algunos "históricos" del PSB continuaron durante las cruciales semanas subsiguientes, lo que ciertamente acabó debilitando su campaña para la primera vuelta. ${ }^{7}$

Un tercer asunto espinoso que provocó desarmonías en la campaña de Marina Silva era concerniente a la manutención de las alianzas regionales que Campos había construido con otros actores políticos, económicos y sociales, y con algunas candidaturas locales. Siendo que algunas de estas alianzas

'Marina se apresenta como candidata do PSB e da renovação política", El Pais, 20.8.2014, disponible en: www.elpais.com.br. Acceso el 3 de noviembre de 2014.

"Marina, em meio a uma briga interna do PSB que ameaça sua campanha", El Pais, 26.9.2014, disponible en: www.elpais.com.br. Acceso el 3 de noviembre de 2014. 
Artigo original

Hegemonia - Revista Eletrônica de Relações Internacionais do Centro Universitário Unieuro

ISSN: $1809-1261$

UNIEURO, Brasília, número 15, 2015, pp. 68-87.

aparentemente no eran del agrado de Marina Silva, especialmente cuando le vinculaban a ciertos intereses del agro negocio o con partidos de otras ideologías. El asunto fue resuelto cuando la nueva candidata aceptó acatar y respetar los pactos y acuerdos firmados por Campos - lo que no modificó su determinación de desdeñar aquellos entendimientos que ella continuase considerando perturbadores o espurios.

Algo muy parecido aconteció con el propio programa de gobierno del PSB, presentado al público en la última semana de agosto. Dicho documento, heredado de la gestión de Campos, presentaba una tendencia liberal en la economía, plausible en lo político, y progresista en el campo social.

Entretanto, ese documento también incluía ciertos tópicos polémicos para la sociedad brasileña, en conjunto, y específicamente para la propia Marina Silva - que siempre se identificó con las poderosas y conservadoras iglesias evangélicas del país. Tal fue el caso, por ejemplo, de las directrices del PSB relacionadas a la responsabilidad fiscal, al aborto, al matrimonio homosexual o a la independencia del Banco Central. Todas ellas acabaron generando no pocas críticas, rectificaciones y aclaraciones. Marina fue acusada de aventurerismo, indefinición, y hasta mesianismo-personalismo. Ello también afecto la credibilidad de la candidatura en su conjunto. ${ }^{8}$

Aun así, parece pertinente resaltar que en plena campaña de primera vuelta Marina Silva logró, inicialmente, recuperar su altísima simpatía e identificación popular. Ella planteaba la posibilidad de impulsar un nuevo estilo de concretizar la política brasileña, buscando siempre estar más cerca de las preocupaciones cotidianas de los ciudadanos - incluso en lo concerniente a los temas de la agenda ambiental. Se trataba de renovar el sistema y la sociedad, mediante la recomposición y la convergencia con las mejores personalidades

"Candidata-surpresa, Marina é vítima de suas próprias contradições", El Pais, 31.8.2014, disponible en: www.elpais.com.br. Acceso el 3 de noviembre de 2014. 
Artigo original

Hegemonia - Revista Eletrônica de Relações Internacionais do Centro Universitário Unieuro

ISSN: $1809-1261$

UNIEURO, Brasília, número 15, 2015, pp. 68-87.

del país - independientemente de afiliaciones partidarias. El mercado financiero, el electorado juvenil y un sector poderoso del empresariado agrícola se identificaron con muchas de esas ideas y propuestas. Marina Silva llegó a ser considerada como una virtual 'Obama brasileña'.

En consecuencia, en los sondeos de intención de votos publicados en la primera quincena de septiembre, Marina Silva empataba con Dilma Rousseff en el primer lugar. Casi todos los medios de comunicación daban por descontado que ambas candidatas irían a la segunda vuelta, y en no pocos sondeos se manifestaba la probable victoria de Marina Silva, en los comicios de 26 de octubre.

Asunción del gobierno y escenario post-electoral

El Brasil emergió de las elecciones de octubre de 2014 con importantes continuidades, mudanzas y desafíos. De modo general, es evidente que las elecciones fueron un exitoso ejercicio de democracia. Millones de electores del inmenso país acudieron a las urnas y escogieron libremente sus candidatos a cargos públicos. Más de 30 partidos políticos inscritos presentaron a los electores una infinidad de candidatos. $Y$ no hubo incidentes graves que comprometiesen los resultados del proceso.

En el plano federal, que es que más interesa para los fines del presente artículo, debemos tomar nota de la - apretada - reelección de la presidenta Dilma Rousseff - con $52 \%$ de los votos en la segunda vuelta - y de alguna renovación en el Parlamento. Con relación a la reelección de la titular del Poder Ejecutivo parece pertinente destacar que Dilma Rousseff asumió, en enero de 2015, su segundo mandato en circunstancias menos favorables, en comparación a las que encontró en 2011.

La situación económica del país es motivo de considerable preocupación, principalmente por el insatisfactorio desempeño macroeconómico - creciente inflación, bajo crecimiento del producto, modestos índices de inversión, decreciente competitividad internacional, déficit fiscal en numerosos 
Artigo original

Hegemonia - Revista Eletrônica de Relações Internacionais do Centro Universitário Unieuro

ISSN: $1809-1261$

UNIEURO, Brasília, número 15, 2015, pp. 68-87.

estados/provincias. Al mismo tiempo, existiría cierto escepticismo en los poderosos gremios empresariales, que ciertamente hubiesen preferido una victoria de la oposición. La designación de las nuevas autoridades del área económica y la recomposición de la confianza entre el empresariado y el gobierno se erigió en uno de los primeros asuntos que fueron discutidos en el marco de la asunción del nuevo gobierno.

En el campo sociocultural, el nuevo gobierno ha tenido que trabajar para reconciliar a la sociedad, después de un proceso electoral particularmente polarizado y agresivo. Acontece que durante la campaña y después de anunciados los resultados de los comicios una verdadera ola de odio, intolerancia y preconceptos político-ideológicos (derecha-izquierda, ricos-pobres, blancos-negros, nordestinos-suristas) se expandió por considerables parcelas del país. Expresiones claramente racistas, segregacionistas y hasta fundamentalistas tomaron cuenta de numerosos medios de comunicación de masas, principalmente en las redes sociales. La contundente victoria petista en las regiones Nordeste y Norte fue objeto de mensajes y manifestaciones espurias. Algunos opositores exaltados llegaron a reivindicar públicamente un golpe militar o un secesionismo territorial. Paralelamente, casi un tercio de los electores se abstuvieron, votaron en blanco o anularon su voto. Aunque se trata de un porcentaje significativo, el mismo es consistente con las tendencias observadas en los últimos procesos electorales del país (Avritzer, 2008). Y ciertamente sugiere que continúa existiendo considerable desafección popular frente a la clase política.

Para apaciguar los ánimos de la oposición, de algunos aliados y de los segmentos más vulnerables de la sociedad, el gobierno tendrá un período relativamente breve, que culminará, como máximo, en 2016, con las elecciones municipales. En tal sentido, parece pertinente mencionar que la agenda sociocultural del nuevo gobierno petista incluye numerosos tópicos espinosos, principalmente relacionados a la reforma agraria, a la demarcación de tierras indígenas, a las reivindicaciones de los movimientos sociales urbanos, y a la reforma de los servicios públicos (especialmente transporte, educación, salud y seguridad pública). 
Artigo original

Hegemonia - Revista Eletrônica de Relações Internacionais do Centro Universitário Unieuro

ISSN: $1809-1261$

UNIEURO, Brasília, número 15, 2015, pp. 68-87.

Simultáneamente, Dilma Rousseff tendrá que trabajar con un Parlamento probablemente mucho más enérgico, proactivo y conservador que legislativos anteriores. El asunto es sensible ya que muchas de las decisiones económicas y sociales mencionadas deberán ser previamente sometidas a la apreciación del Parlamento. La base de sustentación del segundo gobierno dilmista será más o menos parecida. Se trata de una base parlamentaria mayoritaria en el Congreso. Obviamente ello es sumamente importante en términos de gobernabilidad política, principalmente en aquellos países donde predomina el presidencialismo de coalición (Braga e Pimentel, 2011).

Estimase que $60 \%$ de los diputados y de los senadores conforman la nueva base de apoyo del gobierno en el Congreso desde enero de 2015. No se trata de una ventaja confortable o cómoda. La oposición creció y promete ser muchos más dinámica y contundente. Asimismo, ciertos partidos aliados del PT no son totalmente confiables o disciplinados. De hecho no faltan ejemplos de partidos o corrientes internas que actúan dentro de partidos teóricamente aliados que, al no tener atendidas sus demandas por el Ejecutivo, pasan a votar en convergencia con la oposición, imponiendo resultados contrarios a los pretendidos por el gobierno. En otras palabras, la disciplina partidaria no es muy rigurosa en la base de apoyo del Partido de los Trabajadores, principalmente cuando se trata de partidos de centro o de centro-derecha. Algunos analistas políticos sugieren que muchos de los principales escándalos de corrupción de los últimos años se debe, precisamente, a la necesidad de atender las necesidades y los deseos - pecuniarios - de aquellos partidos políticos en el Parlamento.

Se infiere de lo anterior que una reforma política es urgente en el país. Entretanto, el asunto acaba siendo polémico, si de un lado, todos los principales actores políticos concuerdan con esa demanda; de otro, existen grandes divergencias sobre el contenido de dicha reforma política. La imposición de una clausula de barrera ( $5 \%$ del electorado) para garantizar la participación en el Congreso, la modificación del voto y de las alianzas, los ajustes a la ley para evitar la excesiva proliferación de partidos políticos (28 de los 32 partidos políticos inscritos tienen representantes en la actual legislatura brasileña), la redefinición del financiamiento de las campañas (pública, privada o mixta), la verticalización y disciplinamiento del sistema partidario, la redistribución del 
Artigo original

Hegemonia - Revista Eletrônica de Relações Internacionais do Centro Universitário Unieuro

ISSN: $1809-1261$

UNIEURO, Brasília, número 15, 2015, pp. 68-87.

horario gratuito de propaganda electoral, entre otros asuntos, son frecuentemente citados por los analistas como elementos indispensables en una eventual reforma política (Avritzer, 2006).

Adicionalmente, la dinámica del diálogo institucional Ejecutivo-Legislativo podría verificarse aún más tenso por el perfil más conservador del Parlamento electo. En la Cámara de Diputados, por ejemplo, hubo un incremento de representantes vinculados directa o indirectamente al empresariado (urbano y rural), a las iglesias evangélicas, y al estamento judicial-policial. En contrapartida, representantes relacionados a los movimientos sociales principalmente al mundo sindical y al ambientalismo - experimentaron evidente disminución. $Y$ la bancada femenina, que ya era relativamente modesta, continuó estable; obsérvese que la mayoría de las diputadas electas no se identifica prioritariamente con las reivindicaciones de género o de minorías, y si con los temas de los partidos que las eligieron.

En consecuencia, parece evidente que el nuevo gobierno brasileño tendrá que desplegar y hacer gala de una mejor articulación política y social. La agenda doméstica del cuarto gobierno del Partido de los Trabajadores, y de la sociedad en conjunto, es compleja y ciertamente absorberá buena parte del capital político conquistado en las urnas.

Aunque el escenario macro-regional y global no se verifican negativos para los intereses estratégicos o vitales del Brasil - con excepción parcial del poco satisfactorio desempeño del Mercosur -, el tiempo apremia. Construir pactos políticos renovadores tanto con la propia base de sustentación, como con la oposición y con el resto de los actores de la sociedad es necesario y urgente. Las perspectivas son positivas, pero no necesariamente optimistas o idealistas. En tal sentido, vislumbramos que el segundo semestre de 2015 resultará crucial, tanto para la gobernabilidad, el crecimiento y la inserción internacional del Brasil, como para el devenir del segundo gobierno de Dilma Rousseff.

Consideraciones finales 
Artigo original

Hegemonia - Revista Eletrônica de Relações Internacionais do Centro Universitário Unieuro

ISSN: $1809-1261$

UNIEURO, Brasília, número 15, 2015, pp. 68-87.

Desde perspectivas de Prestación de Cuentas Electoral y de Competición Electoral (Morlino, 2011), los comicios de octubre de 2014 fueron un ejemplo exitoso de organización, eficiencia administrativa, transparencia y tecnología. Entretanto, también es evidente que la polarización político-ideológica, junto a graves acusaciones de corrupción en empresas públicas - particularmente en la gigantesca Petrobras -, han derivado en un segundo mandato inesperadamente turbulento para la presidenta Dilma Rousseff.

Paradojalmente, durante el primer semestre de 2015, el nuevo gobierno brasileño ha encontrados importantes dificultades y contratiempos en el Parlamento. Casi siempre son representantes teóricamente aliados, por ser integrantes de la coalición presidencial, más que representantes de la oposición, quienes han demostrado insatisfacción y aplicado algunas pesadas derrotas en proyectos de interés del Ejecutivo. Al mismo tiempo, indicadores de opinión pública sobre el desempeño y sobre la confianza en el gobierno petista han experimentado un sensible deterioro (Cni-Ibope, 2014). Algo semejante se puede afirmar sobre la percepción de la corrupción, del abuso de poder económico, y de otras situaciones semejantes.

Delante de ese complejo panorama en la coalición gubernamental, ciertos segmentos de centro-derecha, han propugnado por una eventual abertura de proceso de destitución de la presidenta, alegando crímenes de responsabilidad.

Sea como fuere, la presidenta Dilma Rousseff fue ungida legítimamente en las urnas, por la mayoría de los electores brasileños. Ella tiene un período de gobierno complejo, especialmente en el marco de las elecciones municipales de 2016. El proyecto social-popular goza de apoyo entre las clases subalternas de la población - aunque es duramente criticado por los sectores más acomodados del país. Así, recomponer las relaciones con su base de sustentación, impulsar reformas económicas y políticas, y auspiciar la transparencia en la administración - mediante una lucha contra la corrupción -, además de promover un mayor dinamismo económico, se vislumbran como imperativos cruciales que definirán el devenir no solamente del cuarto gobierno petista, como de la calidad de la democracia brasileña, en general (Morlino, 2015; Pnud, 2004). 
Artigo original

Hegemonia - Revista Eletrônica de Relações Internacionais do Centro Universitário Unieuro

ISSN: $1809-1261$

UNIEURO, Brasília, número 15, 2015, pp. 68-87.

Referencias bibliográficas

AVRITZER, Leonardo. Reforma política e participação no Brasil. In: ANASTASIA; ANASTASIA, Fátima (Orgs). Reforma política no Brasil. Belo Horizonte: Editora UFMG, 2006, p. 35-44.

- Instituições participativas e desenho institucional: algumas considerações sobre a variação da participação no Brasil democrático. Opinião Pública, v. 14, n. 1, p. 43-64, 2008.

BRAGA, Maria. Eleições e democracia no Brasil: a caminho de partidos e sistemas partidários institucionalizados. Revista Brasileira de Ciência Política, n. 4, p. 43-73, 2010.

; PIMENTEL, Jairo. Os partidos políticos brasileiros realmente não importam? Opinião Pública, v. 17, n. 2, p. 271-303, 2011.

CARREIRÃO, Yan; KINZO, Maria. Partidos políticos, preferência partidária e decisão eleitoral no Brasil (1989/2002). Dados, v. 47, n. 1, p. 131-168, 2004.

CEPAL. Panorama Social de América Latina - 2014. Santiago de Chile: Nações Unidas, 2014.

CNI-IBOPE. Pesquisa CNI-IBOPE Avaliação do Governo - Dezembro de 2014, v. 4, n. 4, 2014. Disponível em http://www.cni.org.br.

D'ARAÚJO, Maria. Sobre Partidos e Qualidade da Democracia no Brasil, Desigualdade e Diversidade, n. 5, p. 217-238, 2009.

IPEA. (2012) Nota Técnica. Gasto Social Federal: prioridade macroeconômica no período 1995-2010. Disponível em http://www.ipea.gov.br

LATINOBARÓMETRO. Informe Latinobarómetro 2013. Santiago de Chile: Corporación Latinobarómetro, 2013.

LIMONGI, Fernando; CORTEZ, Rafael. As eleições de 2010 e o quadro partidário. Novos Estudos Cebrap, n. 88, p. 21-37, 2010.

MAINWARING, Scott. Sistemas partidários em novas democracias: o caso do Brasil. Rio de Janeiro: FGV, 2001.

MOISÉS, José. A Corrupção Afeta a Qualidade da Democracia? Em Debate, v. 2, n. 5, p. 27-37, 2010. 


\section{Artigo original}

Hegemonia - Revista Eletrônica de Relações Internacionais do Centro Universitário Unieuro

ISSN: $1809-1261$

UNIEURO, Brasília, número 15, 2015, pp. 68-87.

MORLINO, Leonardo. What qualities of democracy in Latin America? Mixing quantitative and qualitative analyses. In: XAVIER, Lígia; DOMÍNGUEZ, Carlos (Orgs.) Política, Cultura e Sociedade na América Latina: Estudos Interdisciplinares e comparativos. V. 2, Curitiba: CRV, p. 17-51, 2015.

. Changes for Democracy: Actors, Structures, Processes. Oxford: Oxford University Press, 2011.

PNUD. A Democracia na América Latina/ Idéias e contribuições. Santana do Parnaíba: Nações Unidas, 2004.

SANTANDER, Carlos; et alli. Calidad de la Democracia en Brasil. Anales del 7 Congreso de Alacip. Bogotá: Red de Estudios sobre la Calidad de la Democracia en América Latina, 2014.

TELLES, Helcimara; MORENO, Alejandro. Comportamento Eleitoral $e$ Comunicação Política na América Latina. O eleitor latino-americano. Belo Horizonte: Editora Ufmg, 2013. 